\title{
Heterochromatin readjusting chiasma distribution in two species of the genus Arcyptera: The effect among individuals and populations
}

\author{
J. de la Torre, \\ C. López-Fernández, \\ R. Nichols* and \\ J. Gosálvez
}

Dpto. de Genética C-XV, Facultad de Ciencias, Universidad Autónoma de Madrid, Madrid 28049, Spain.

Chiasma variation has been studied in two selected chromosomes from two species of the genus Arcyptera according to the heterochromatin distribution per bivalent.

The differences in chiasma distribution found between each karyomorph revealed an underlying tendency for chiasmata to occupy characteristic positions in the bivalents depending on the heterochromatin distribution. It seems that the heterozygosity of the bivalent more than the presence of heterochromatic segments is readjusting a standard pattern of chiasma distribution.

The findings of this survey are discussed in relation to the significance and role of genetical recombination in natural populations depending on the frequency of karyomorphs per populations and the pattern of chiasma distribution per individual.

\section{INTRODUCTION}

One of the most common polymorphisms found in Orthoptera and in eukaryotes in general is the presence or absence of heterochromatic segments. Most of these segments are constitutive heterochromatin, and segments of such material are associated with characteristic effects on the chiasmata in some organisms. These occur in three ways: (a) inhibiting chiasma formation in the region of the constitutive heterochromatin (Fox et al., 1973), (b) modifying the basic pattern of chiasma distribution in the bivalents heterozygous or homozygous for the segments (Miklos and Nankivell, 1976; John, 1981; John and King, 1982; García-Lafuente et al., 1983) and (c) affecting the recombination in other bivalents. This last situation usually involves an increase in mean cell chiasma frequency (John and Hewitt, 1966) or between cell variance (Shaw, 1971a, b).

By altering recombination, such segments affect the genotypic variation in the progeny, and any feature capable of modifying recombination

\footnotetext{
* School of Biological Sciences, University of East Anglia, NR4 7TJ. Norwich, England.
}

can have potentially important effects to the population (e.g., Shaw et al., 1980). With this in mind we have analysed the effect of heterochromatic segments on chiasma distribution in two selected short bivalents of two species of Acridoids. This enabled us to ascertain if heterochromatic material is involved in the readjustment of the distribution within the bivalents, and if other factors must be considered in a model to explain the observed changes.

\section{MATERIAL AND METHODS}

Male grasshoppers belonging to the species Arcyptera fusca and $\boldsymbol{A}$. tornosi, collected from natural populations in the Pyrenees and Sierra de Gredos respectively, were utilised for the investigation. Testes were removed and fixed in acetic-acid: ethanol $(3: 1)$. Preparations were processed for C-banding following the technique of LópezFernández and Gosálvez (1981). The number of individuals which were used in this investigation are listed in table 1 and 2 . Short bivalents, polymorphic with respect to the presence/absence of distal heterochromatic segments (bivalents $S_{10}$ and $S_{11}$ 
Table 1 The distribution of the $S_{11}$ karyomorphs (observed and expected) in the three populations of $A$. tornosi used in the present analysis. Note Hardy-Weinberg equilibrium for all the cases

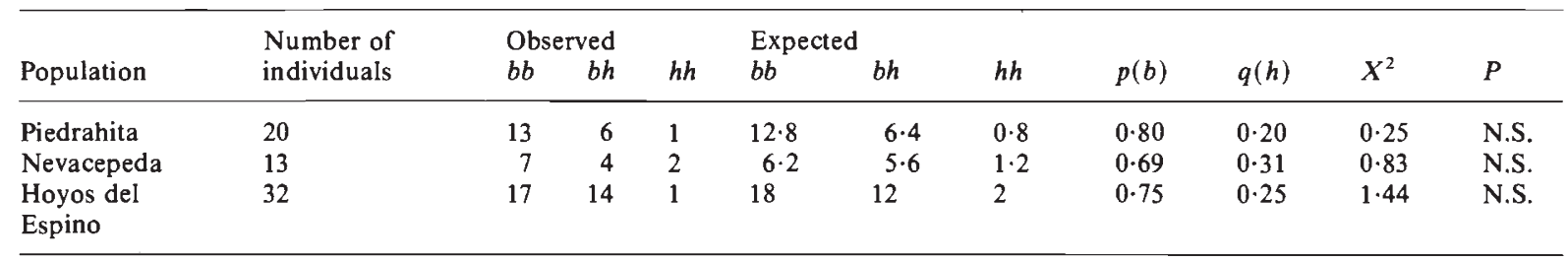

Table 2 The distribution of the $S_{11}$ karyomorphs (observed and expected) in the six populations of $A$. fusca used in the present analysis. Note Hardy-Weinberg equilibrium for all the cases

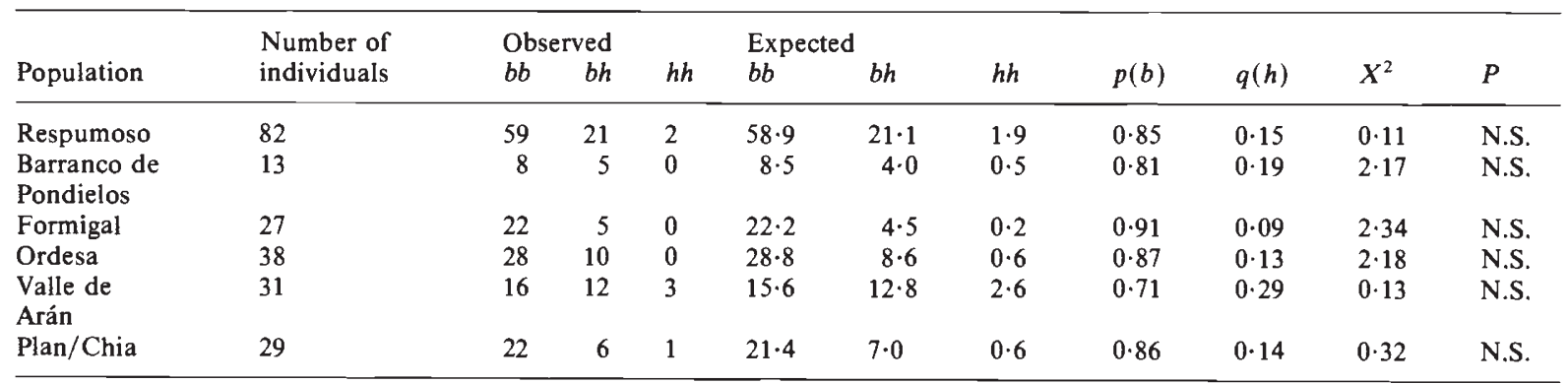

in both species), were selected for the analysis of chiasma localisation. The position of the single chiasma was scored by eye at diplotene from the shape of the bivalent, as depicted in fig. 2 and 4 .

\section{RESULTS}

\section{The karyotype and heterochromatin distribution}

Both species of the genus Arcyptera included in this analysis have a karyotype consisting of two long $\left(L_{1}, L_{2}\right)$, six medium $\left(M_{3}-M_{8}\right)$ and three small pairs $\left(S_{9}-S_{11}\right)$ of autosomes and an XO/XX sex chromosome system (fig. 1). Arcyptera fusca has distal constitutive heterochromatic segments in pairs $M_{4}$ to $S_{11}$ (fig. 1). Pairs $M_{4}, M_{6}, S_{9}, S_{10}$ and $S_{11}$ may be polymorphic due to the presence or absence of such segments. This polymorphic system can be compared to that in Arcyptera tornosi. This has an identical chromosome number and the heterochromatic segments are found in all bivalents from $M_{5}$ to $S_{11} . M_{6}, S_{10}$ and $S_{11}$ are polymorphic for such segments in all the populations studied. Segments on the $M_{5}$ pair are very faint and only visible in very good banding preparations.

In this paper we concentrate attention on bivalents which exhibit only one chiasma and are polymorphic for these segments, that is the $S_{10}$ and $S_{11}$ in both species (fig. 1). All these segments are

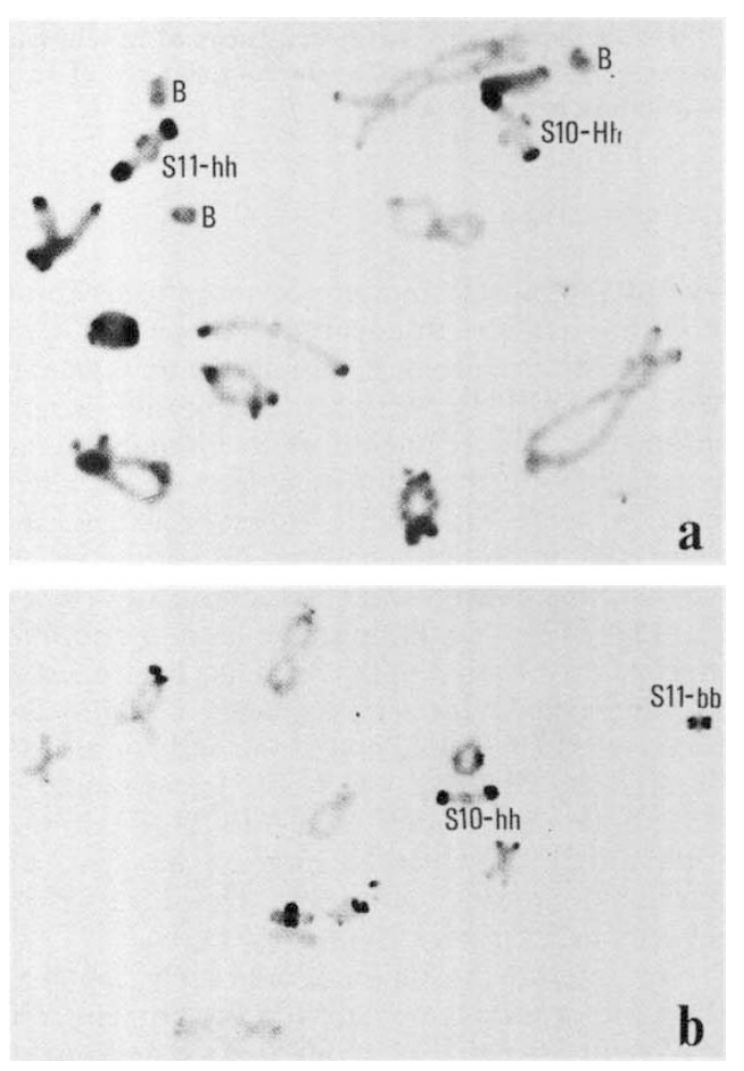

Figure 1 C-banded diplotenes from Arcyptera fusca (1a) and A. tornosi (1b). 


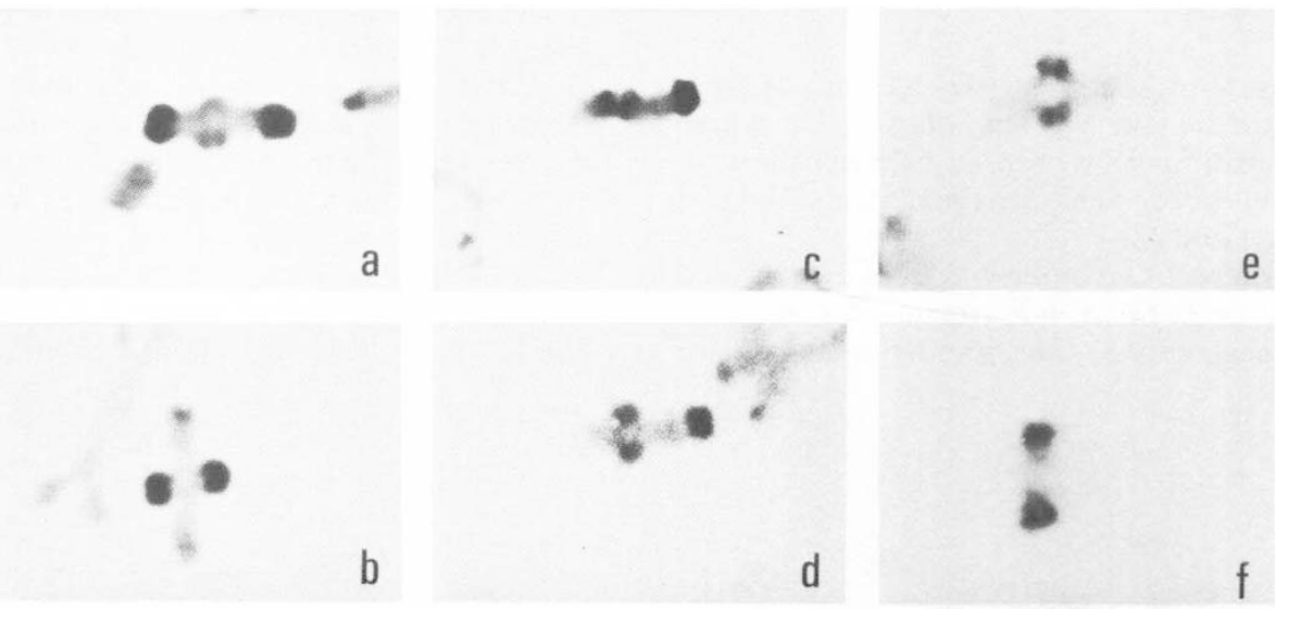

Figure 2 Chiasma distribution in the $S_{11}$ bivalent of $A$. fusca depending on its heterochromatic content. a) hh bivalent with a proximal chiasma, b) $h h$ bivalent with a distal chiasma, c) $b h$ bivalent with a chiasma beyond the centromere?, d) $b h$ bivalent with a proximal chiasma, e) $b b$ bivalent with a proximal chiasma, f) $b b$ bivalent with a distal chiasma.

positively C-banded and occur in three different karyomorphs: $b b$ (without heterochromatic segments), $b h$ (with one heterochromatic segment) and $h h$ (with two heterochromatic segments). The size of the segments may also vary, giving rise to individuals heterozygous for the size of such segments $(h H)$.

\section{The $S_{11}$ bivalent}

An analysis of C-banded diplotene cells showed that chiasmata were found either i) near the centromere (proximal chiasma, fig. $2 \mathrm{a}, 2 \mathrm{~d}$ and $2 \mathrm{e}$ ) or ii) near the telomere (distal chiasma, fig. $2 b$ and 2f). Clear interstitial chiasmata were never found.

A third category of association was found in heterozygous bivalents (fig. 2c). This could be interpreted as a chiasma placed in a short arm beyond the centromere; this would mean that these bivalents are in fact acrocentrics. Selective staining of the kinetochores with silver nitrate (Rufas et al., 1983) has demonstrated the existence of a short arm in these species which supports this interpretation. However, it may be an example of an achiasmate heterochromatin association as has been suggested in similar cases (Gosálvez and LópezFernández, 1981; John and King, 1982). It is not possible to distinguish these alternatives and in any event the interpretation does not affect the conclusions of the present experiments.

In the case of $A$. fusca both homozygous bivalents $\left(S_{11}-b b\right.$ or $\left.S_{11}-h h\right)$ show a high frequency of chiasmata in distal regions (fig. 3 ) while in heterozygous bivalents $\left(S_{11}-b h\right)$, this pattern is clearly different (fig. 3): no chiasmata are found in the distal region and an appreciable number were detected in the short arms.

There are two main differences between $A$. tornosi and $A$. fusca. In the $S_{11}-b b$ karyomorph of $A$. tornosi the short arm forms a chiasma at an appreciable frequency and in $S_{11}$-hh individuals there is a higher frequency of proximal chiasma.
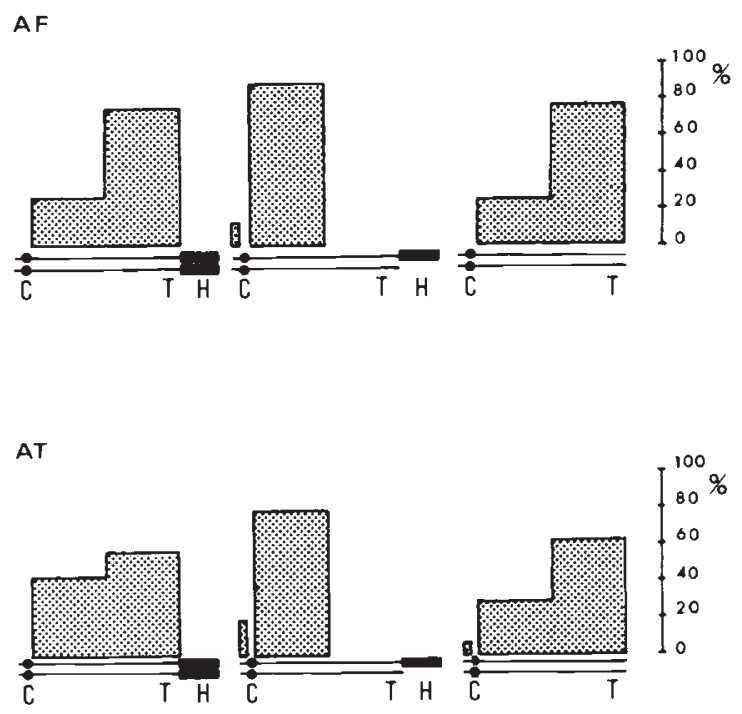

Figure 3 Chiasma distribution in the $S_{11}$ bivalents. AF represents the distribution obtained for $\boldsymbol{A}$. fusca according to the three karyomorphs. AT represents the distribution obtained for $A$, tornosi according to the three karyomorphs. 


\section{The $S_{10}$ bivalents}

The $S_{10}$ bivalents in both species have much more euchromatin than the $S_{11}$. This allows at least three chiasma positions to be scored between the centromere and the segment: proximal, interstitial and distal (fig. 4 and 5).

Two different karyomorphs could be analysed in the case of $A$. fusca: homozygous for the presence of a segment $\left(S_{10}-h h\right)$, and heterozygous for the size of the segment on each homologue $\left(S_{10^{-}}\right.$ $H h)$. These differ considerably in chiasma distribution. In the $S_{10}-h h$ bivalents, chiasmata are usually distally positioned (fig. 5), in the heterozygous $S_{10}-H h$ the distribution is shifted towards the centromere giving a high frequency of proximal chiasmata (fig. 5).

It was possible to conduct a more detailed analysis of the $S_{10}$ bivalent in $A$. tornosi because there were four different combinations of
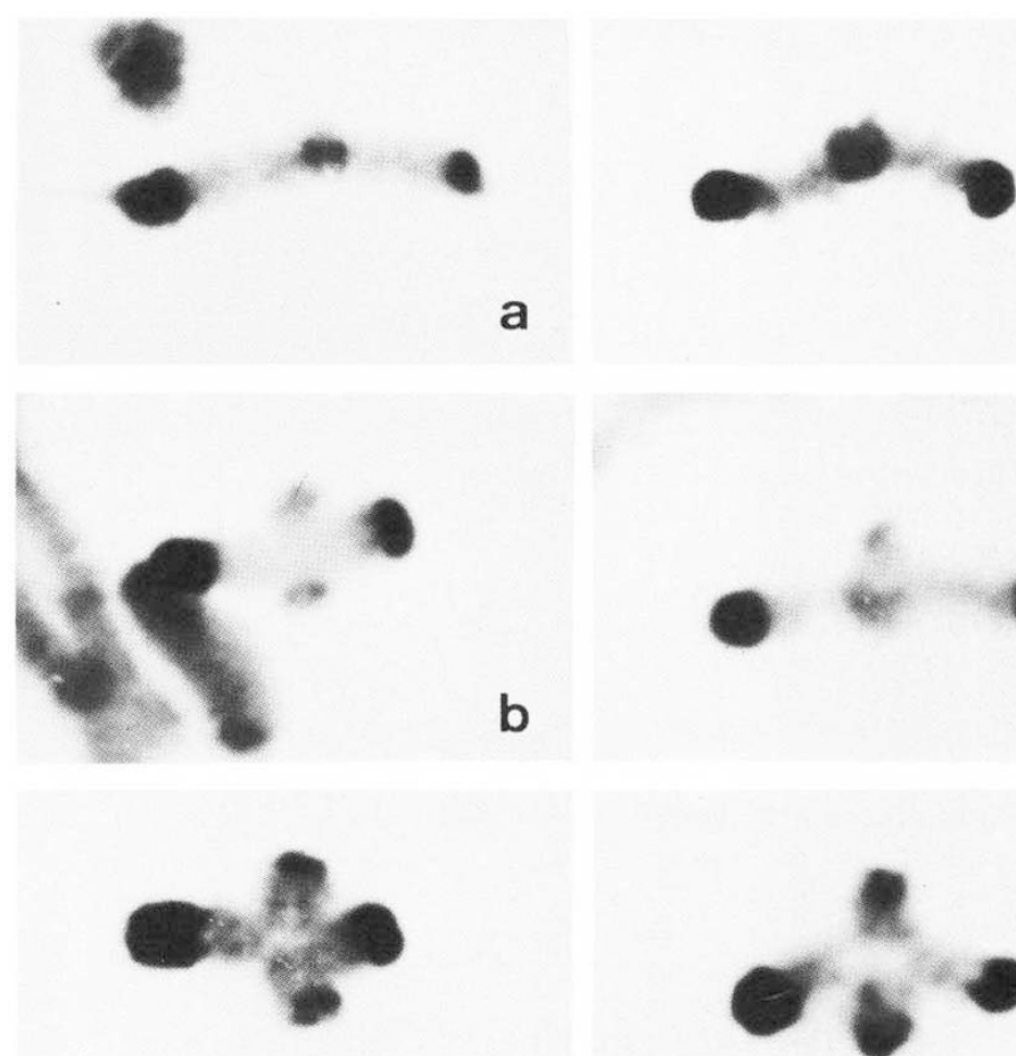

a

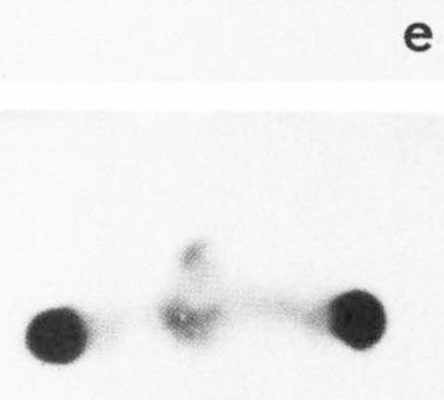

b

f

C

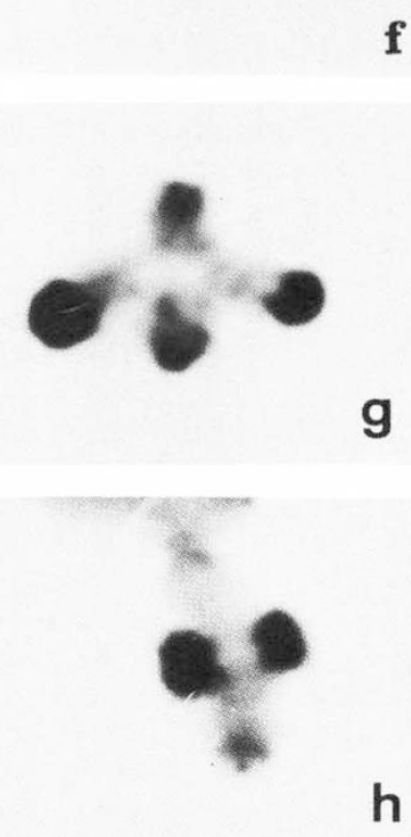

Figure 4 Chiasma distribution in the $S_{10}$ bivalent of $A$. fusca depending on its heterochromatic content. a, b, c, d,) chiasma beyond the centromere?, proximal, intersticial and distal chiasma respectively in a heterozygous $H h$ karyomorph. e, f, g, h,) chiasma beyond the centromere?, proximal, interstitial and distal chiasma respectively in a homozygous $h h$ karyomorph. 


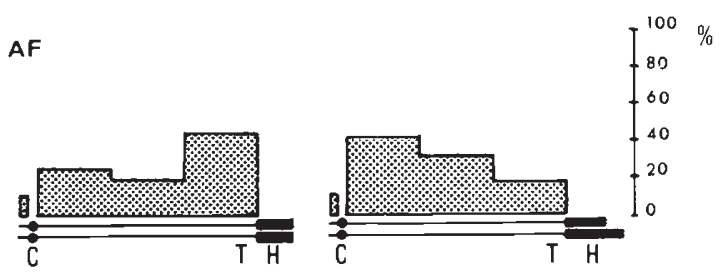

AT

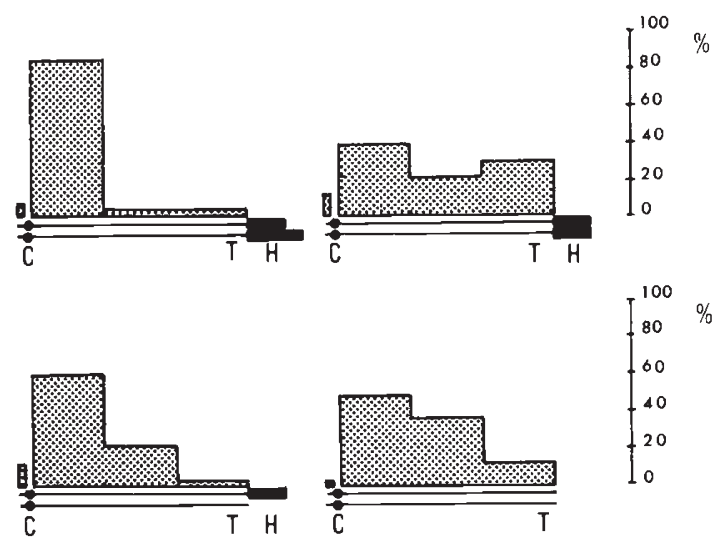

Figure 5 Chiasma distribution in the $S_{10}$ bivalent. AF represents the distribution obtained for $A$. fusca according to the two karyomorphs. AT represents the distribution obtained for A. tornosi according to the four karyomorphs.

heterochromatic segments available, viz $S_{10}-b b$, without heterochromatic segments; $S_{10}-b h$, with one short segment affecting one homologue; $S_{10^{-}}$ $h h$, with two short segments; $S_{10}-H h$, a heterozygous bivalent for the size of the segments involved.
The results obtained in these cases were quite consistent with those described above. In both heterozygous types $\left(S_{10}-b h\right.$ and $\left.S_{10}-H h\right)$ the chiasmata are frequently localised near the centromere although the effect is less marked than in the previous examples, as a high frequency of chiasma was also found in the centromeric region of the basic bivalent $\left(S_{10}-b b\right)$. An appreciable frequency of a "chiasma" was found beyond the centromere irrespectively of the heterochromatic characteristics of the bivalent.

\section{DISCUSSION}

\section{The effects on the bivalent}

It has been long evident that the amount of heterochromatin may vary from individual to individual within a species or between populations of the same species. This variation has been especially well documented in grasshoppers (Shaw et al., 1976; White and Contreras, 1981). The use of Cbanding allows detailed studies of the extensive heterochromatic variation present in many natural populations. In this study a highly significant association was found between chiasma location and the presence of distal heterochromatic segments. There was no significant variation detected in chiasma distribution amongst individuals of the same karyotype (table 3); it appears that the heterochromatic segments account for the major differences. In the cases studied, the most distinct difference was apparent when both homozygotes ( $b b$ or $h h$ ) are compared with the heterozygotes (bh or $H h$ ). This evidence led us to consider the possibility of a direct relationship between chiasma

Table 3 A comparison between the chiasma distribution amongst individuals of the same karyotype. No significant differences were observed

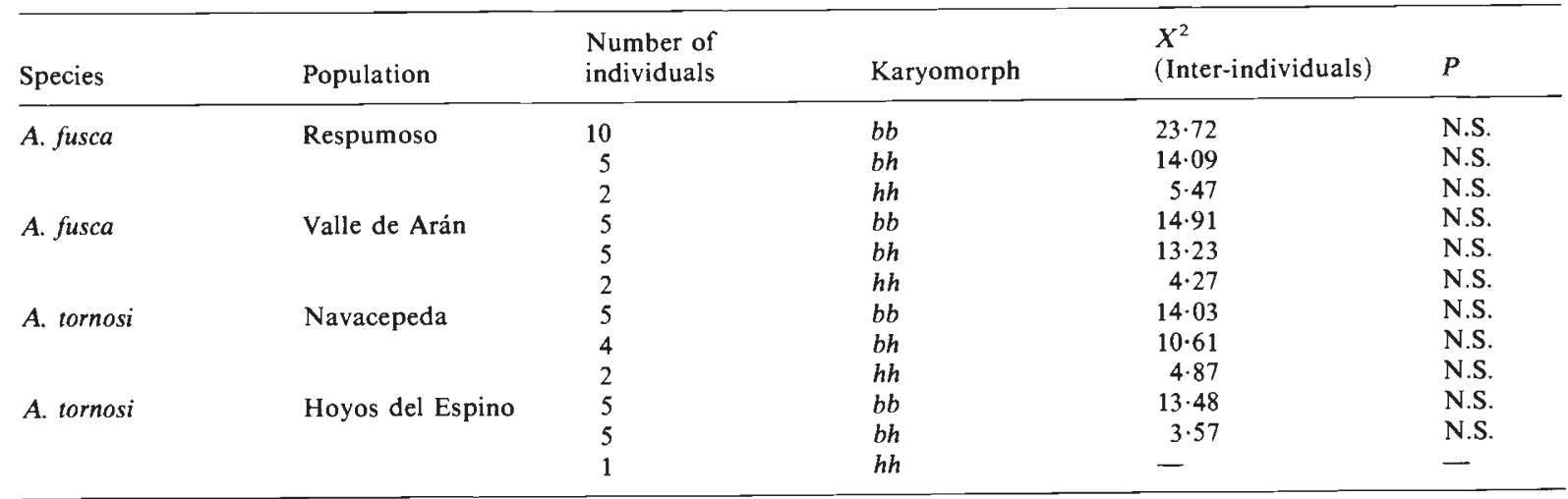



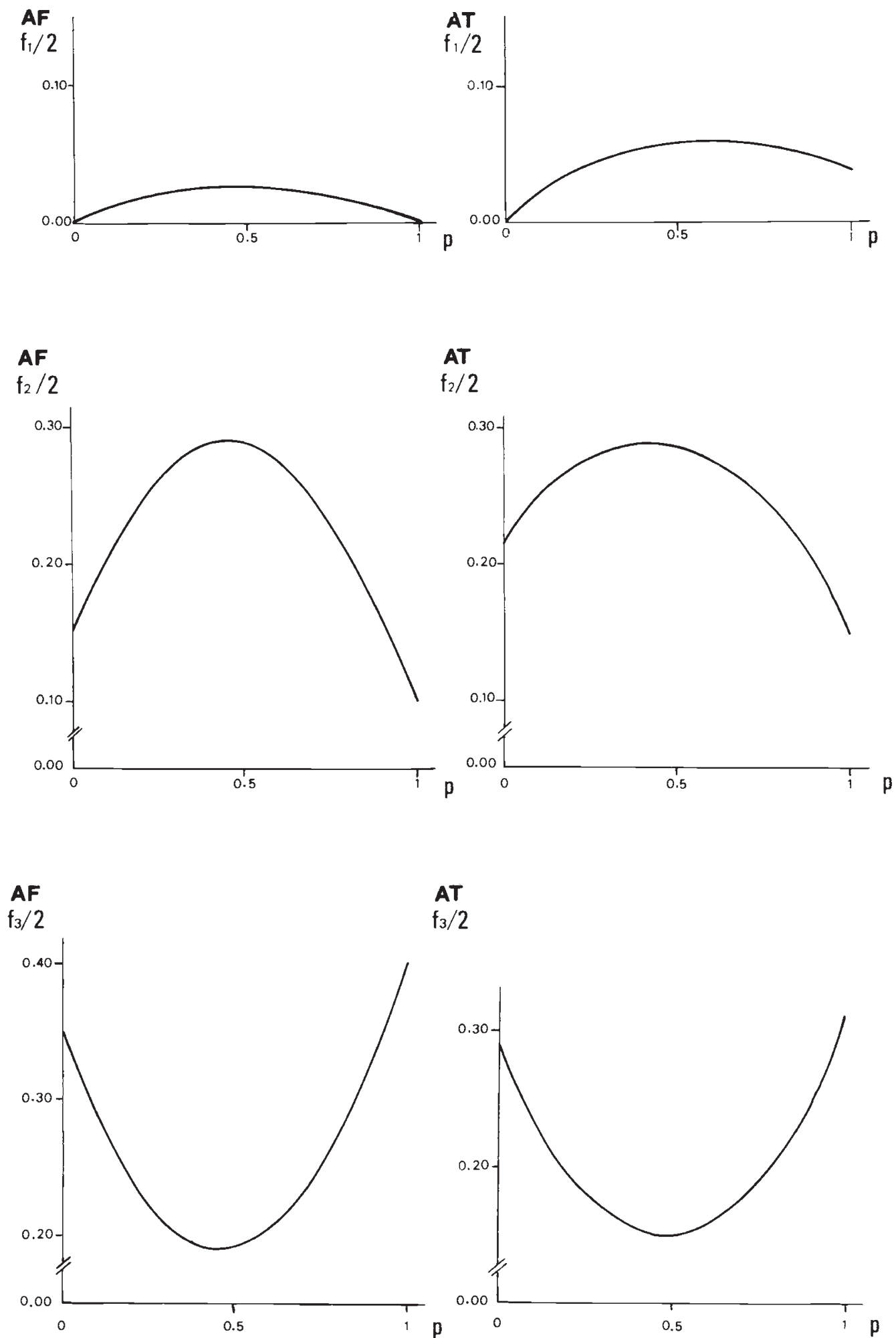

AT

$f_{3} / 2$

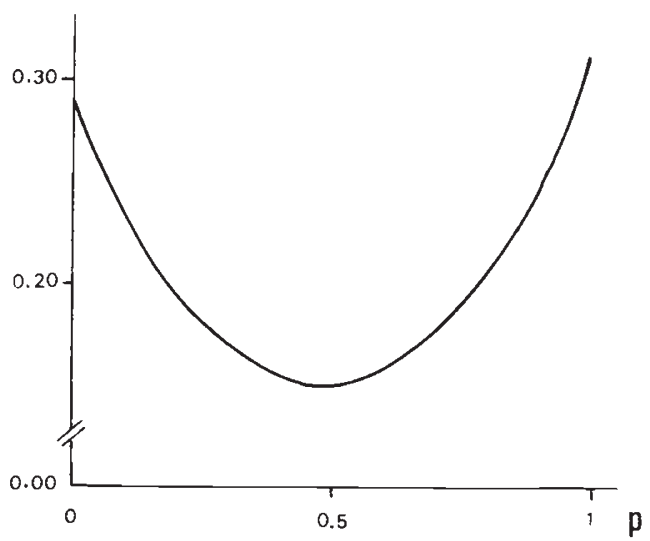

Figure 6 A graphic representation of the $f i$ functions depending on the $p$ frequency in the population for the $S_{11}$ chromosome of A. fusca (AF) and A. tornosi (AT). Top: chiasma beyond the centromere, middle: proximal chiasma, bottom: distal chiasma. 
localisation and the formation of a regular synaptonemal complex (SC).

It is possible that the effect of the heterochromatin on the pattern of chiasma distribution may be related to the pairing process. The heterochromatic segment may impair the attachment of the telomeres to the nuclear membrane in heterozygous bivalents, and consequently lead to modifications or asymmetries in the structure of the SC. The disruption of the pairing experienced by some heterozygous bivalents may explain the increased frequency of chiasmata in other regions where the pairing may be achieved with less difficulty. Such disruption could explain the dramatic effects seen in Gomphocerus sibiricus: univalents are detected at diplotene and subsequently more unpredictably at anaphase-I (see fig. in Gosálvez et al. 1982). Similarly, in the grasshopper Leptysma argentina there is a polymorphism for a large interstitial heterochromatic supernumerary segment in a short bivalent which impedes pachytene pairing of the distal euchromatic region and the single chiasma is invariably formed proximally (Bidau, 1984).

If a similar mechanism explains the differences in chiasma distribution between the various karyotypes of Arcyptera, then it may prove possible to detect modifications of the SC in the heterozygotes. The method of Jones et al. (1983) is currently being applied in Arcyptera to this end.

\section{The effects on the population}

It is apparent that supernumerary heterochromatin can affect the range of genetic combinations found in the gametes. Thus, combinations may be found in populations containing heterochromatic segments, which are rare in, or absent from populations which do not.

The evidence suggests that chiasma distribution is consistent in individuals with the same karyotype (table 3) and that the karyotypes are in HardyWeinberg proportions (table 1 and 2).

If this is consistently the case, then the expected chiasma distribution in a population can be calculated from the frequency of the heterochromatic segments $(q)$.

Where there is one segment segregating in the population, the expected frequencies of the three karyotypes will be $p^{2}, 2 p(1-p)$ and $(1-p)^{2}(b b$, $b h$ and $h h$ respectively). The frequency of chiasma in a particular section of a chromosome (i) can be represented as $a i$ (in $b b), b i$ (in $b h$ ) and $c i$ (in $h h$ ). The total frequency of chiasma in this section $(f i)$ will then be $p^{2} a i+2 p(1-p) b i+(1-p)^{2} c i$. This can be re-arranged to give:

$$
f i=p^{2}(a i+c i-2 b i)+2 p(b i-c i)+c i .
$$

$\mathrm{fi} / 2$ is the frequency of gametes produced by recombination in section (i) (as only 2 of the 4 chromatids are involved). The function $f i / 2$ has been drawn for the three sections of $S_{11}$ in $A$. fusca and $A$. tornosi (fig. 6).

In both cases the gametic frequency of the most common type of recombinant can vary by over 20 per cent depending on $q$ (the frequency of the heterochromatic segment).

The largest differences are predicted between populations with intermediate frequencies of heterochromatic segment $(p=0 \cdot 5)$ and fixed populations $(p=1$ or 0$)$. This reflects the large difference in chiasma distribution between homozygotes and heterozygotes.

Differential selection for the various recombinants would result in selection of the heterochromatic segment. The curvilinear nature of the functions $f i$ illustrate the expectation that this selection would be strongly frequency-dependent.

Acknowledgements The authors sincerely thank Dr G. H. Jones, Dr J. Loidl and Dr C. García de la Vega for valuable discussions. The investigation was supported by CAICYT (Spain) and by a grant awarded to Dr G. M. Hewitt and Dr J. Gosálvez from MEC (Spain) and the British Council (UK).

\section{REFERENCES}

BIDAU, C. J. 1984. Meiotic pairing and chiasma localization in Scyllina signatipennis (Gomphocerinae, Acrididae). Caryo logia, 37, 87-103.

FOX, D. P., CARTER, K. C. AND HEWITT, G. 1973. Giemsa banding and chiasma distribution in the desert locust. Heredity, 31, 272-276.

GARCIA-LAFUENTE, R., LÓPEZ-FERNÁNDEZ, C. AND GOSÁlVEZ, J. 1983. Extra heterochromatin in natural populations of Gomphocerus sibericus (Orthoptera: Acrididae). 2. Chiasma distribution in the $M 7$ bivalent. Cytobios, 37, 149-155.

GOSÁLVEZ, J. AND LÓPEZ-FERNÁNDEZ, C. 1981. Extra heterochromatin in natural populations of Gomphocerus sibiricus (Orthoptera: Acrididae). Genetica, 56, 197-204.

GOSÁlVEZ, J., LÓPEZ-FERNÁNDEZ, C. AND GARCIALAFUENTE, R. 1982. A spontaneous translocation heterozygote involving centromere region in Gomphocerus sibiricus (Orthoptera: Acrididae). Chromosoma, 86, 49-57.

JOHN, B. 1981. Heterochromatin variation in natural pepulations. Chromosomes today, 7, 128-137. George Allen \& Unwin.

JOHN, B. AND HEWITT, G. 1966. A polymorphism for heterochromatic segments in Chorthippus parallelus. Chromosoma, 18, 254-271.

JOHN, B. AND KING, M. 1982. Meiotic effects of supernumerary heterochromatin in Heteropternis obscurella. Chromosoma, $85,39-65$. 
JONES, G. H., CROFT, J. A. and WALLACE, B. M. N. 1983. Synaptonemal complexes in surface spread preparations of orthopteran spermatocytes. Kew Chromosome Conference II, 123-130. George Allen and Unwin. London.

LÓPEZ-FERNÁNDEZ, C. AND GOSÁlVEZ, J. 1981. Differential staining of a heterochromatic zone in Arcyptera fusca (Orthoptera: Acrididae). Experientia, 37, 240-241.

MIKLOS, G. L. G. AND NANKIVELL, R. N. 1976. Telomeric satellite DNA functions in regulating recombination. Chromosoma, 56, 143-167.

RUFAS, J. S., GOSÁlVEZ, J., GIMENEZ-MARTIN, G. AND ESPONDA, P. 1983. Localization and development of kinetochores and a chromatid core during meiosis in grasshoppers. Genetica, 61, 233-238.

SHAW, D. D. 1971a. The supernumerary segments system of Stethophyma. II. Heterochromatin polymorphism and chiasma variation. Chromosoma, 34, 19-39.
SHAW, D. D. 1971b. Genetic and environmental components of chiasma control. I. Spatial and temporal variation in Schistocerca and Stethophyma. Chromosoma, 34, 281-301.

SHAW, D., MORAN, C. AND WILKINSON, P. 1980. Chromosomal reorganization, geographic differentiation and the mechanism of speciation in Caledia. Insect Cytogenetics, 171-194. Eds. Blackman, R. L., Hewitt, G. M., Ashburner, M.

SHAW, D. D., WEBB, G. C. AND WILkINSON, P. 1976. Population cytogenetics of the genus Caledia (Orthoptera: Acrididae). II. Variation in the pattern of C-banding. Chromosoma, 56, 169-190.

WHITE, M. J. D. AND CONTRERAS, N. 1981. Chromosome architecture of the parthenogenetic grasshopper Warramaba virgo and its bisexual ancestors. Chromosomes today, 7, 165-175. 